\title{
Structural diversity of oak forests in Kurdistan Province (Case study: Oak forest)
}

\author{
Maziar Haidari $^{* 1}$, Naghi Shabanian ${ }^{2}$, Reza Hossein Haidari ${ }^{3}$ and Mozhgan Bazyar ${ }^{4}$ \\ ${ }^{1 *}$ Young Researchers Club, Sanandaj Branch, Islamic Azad University, Sanandaj, Iran. \\ 2- Assistant Prof., Faculty of Natural Resources, University of Kurdistan, Sanandaj, Iran. \\ 3- Assistant Prof., Faculty of Natural Resources, University of Razi, Kermanshah, Iran. \\ 4- M.Sc. Graduate of forestry, University of Gilan, Some-sara, Iran
}

\begin{abstract}
In order to investigate structural diversity of oak forest, Blake forest in the Baneh region, Kurdistan Province was selected. Inventory sampling by random method and three sample plots $(100 \mathrm{~m}$ by100 $\mathrm{m})$ were sampled. In every sample plot the number of tree and shrub species, diameter at breast height (DBH) and height $(m)$ was recorded. Analyses of biodiversity were done using heterogeneity indicators of Shannon Wiener $\left(H^{\prime}\right)$ and Simpson (1-D) as well as evenness using Margalef $\left(R_{l}\right)$ indices. The diameter divided in $10 \mathrm{~cm}$ classes and the height divided in $4 \mathrm{~m}$ height classes and dominant height. Anova was used to analysis all indices means differences in the DBH classes and high classes. To analysis data use the Pest software. Results indicated that Rosacae families have the highest number of species. Quercus libani Oliv and Quercus infectoria Oliv were the most dominant woody plants. The results showed with increase of diameter and height classes species diversity decreased. A significant different was observed between tree diversity of the diameter and height classes (level of 1\%). Thus, the study of biodiversity changes in different diameter and height category cause ecologically precise perspective in management of forest stands.
\end{abstract}

Key words: Diameter and height classes, Iran, Kurdistan, Structural diversity, Zagros forests.

\section{Introduction}

Forests cover about 12 million ha in Iran [22]. The Zagros forests cover a vast area of the Zagros mountain ranges stretching from Piranshahr (Western Azerbaijan Province) in the northwest of the Iran to the vicinity of Firooz-Abad (Fars Province), having an average length and width of $1300 \mathrm{~km}$ and $200 \mathrm{~km}$, respectively [21]. These forests cover approximately an area of 5 million ha, and because of dominancy of species of oak genus, these forests are called as western oak forests [13]. Zagros is typically characterized by a semi-humid climate with extremely cold winters and annual precipitation exceeding $800 \mathrm{~mm}$. The main species in this region are Quercus spp. (oaks), Pistacia mutica (wild pistachio), Crategus spp. and Pyrus spp [23]. Most of the forests of Iran involve some kind of conventional ownership, either communal (by villages) or among families within villages. In the Zagros Mountains, especially in the northern areas, the territory of Kurdish people, this kind of conventional ownership and relationships between humans and nature are extremely strong [13]. Increasing population, low level of development and high dependence of local communities on forests for their primary livelihood needs, are the main reasons of this destruction. The lack of regeneration in these forests is a major concern [8 and 13].Traditional forest management is used in Zagros for the collection of foliage (fodder) for domestic animal. Individual households manage their privately owned forests as unit. The owners of each section regulate tree growth by pruning the crowns using a method called " coppicing". Harvesting is conducted solely by family members unless the family is small. Households with small families receive help from the community. This assistance is called "Gale" (Gala on Kurdish language). One of the traditional forest management practices in the Kurdistan province is prune tree crowns and regulate yields (Armardeh (Blake Village) pattern). In this method is branch selection: cut lateral seedling growing in branches that are less than 5 $\mathrm{cm}$ thick, leaving on branch to grow. The remaining branch will contain a higher concentration of nutrients, making is suitable for future us as lumber [9]. One of the constant keys of management of uneven age forest is the true understanding about spatial structure of forest [6].Forest structure is the important feature in management of forest ecosystems [20]. Structural features are used to determine the species neech heterogeneous experiment and plant dynamic time, management of regeneration patterns and fragmentation dynamic, description of microclimate diversity and predicting the wood production [19].Management of forest stands performs by stands structure control (age, size and tree density) and forest structure (size and spatial order of tree) because the concept of forest structure is more important than species combination [24]. The study of forest structure especially in virgin forests is very important and gives us comprehensive information about the condition in forest for programming. The diversity of a forest stand may not be sufficiently described by tree 
species diversity alone. Structural diversity, resulting from recruitment of trees of different sizes into multilayered canopies, should also be taken into account [11]. This characteristic, which can be approximated by the diversity of tree size, affects the amount of light and precipitation received by subordinate trees and understory plants [2], and may thus influence the productivity of forest ecosystems. There are various studies done about forest structure. The study of natural forests structure defined the way of desired structure that the use of appropriate silviculture operation and stimulation of natural structure in under management stands considered as the way to keep the biological diversity and forest dynamic and stability [11]. The investigated tree species diversity based on the diameter class in Acer sites in Shafarud forests. Biodiversity accounted in four diameter classes (10-30, 35-50, 55-80, and 80-120 cm). The result showed that the Shannon and N1 Mac Arthur indices in diameter class of $35-50 \mathrm{~cm}$, have greatest amount, while the index of Simpson and N2 hill shows the greatest amount in diameter class of 10-30 cm [1]. The evaluated structural diversity of Carpinus betulus stand in Golestan Province, North of Iran. Their results showed that with increasing diameter and height classes, species diversity decreases. Moreover, diversity of regeneration layers had significant difference with tree layers. Thus, the study of biodiversity changes in different diameter and height category cause ecologically precise perspective in management of forest stands [18]. Researchers showed diameter and height classes below of $10 \mathrm{~cm}$, account as $10 \mathrm{~m}$ and regeneration layer have maximum of tree diversity, so diversity of regeneration layer is more than the diversity of tree layers [17 and 18]. The aim of this study is evaluating of the structural diversity in diameter and height classes and that how they change with diameter classes and height category in Quercus spp (oak forest) type in Kurdistan province, Iran.

\section{II.1,Site description}

\section{Materials and Methods}

Iranian habitats support about 8000 species of flowering plants (belonging to 167 families and 1200 genera), of which almost 1700 are endemic [25].This plant species growing on four ecological zones (Figure 1). The Zagros Mountains are divided into two parts of northern and southern. The northern Zagros is consisted of the growing site of Quercus infectoria Oliv and somewhat Q.libani Oliv and Q.persica J. \& Sp. (Q.brantii Lindl.) can be observed. While, the southern Zagros is included Q.persica sites which have extended to Fars province (i.e., $29^{\circ} 5^{\prime} \mathrm{N}$ ). The northern Zagros is wetter and cooler than the southern one. The dispersion areas of Lebanon oak (Q.libani) are mostly restricted to central and eastern mountains of Tavrous and Amanous of Anatolia in Turkey, the mountains of northeastern of Iraq and northwestern of Syria and western part of Iran (i.e., Kurdistan province) [25].

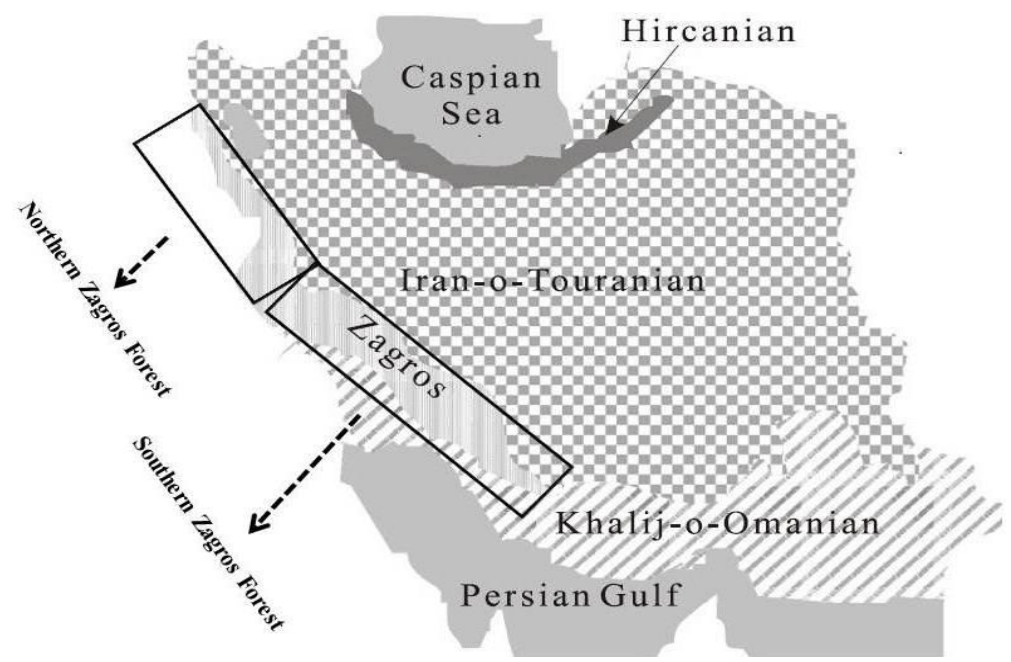

Figure 1. Distribution of four ecological zones of Iran

To study structural diversity of oak forests, Blake forest was selected in the western Iranian state of Kurdistan (Figure 1). Annual precipitation in the Baneh region is approximately $600 \mathrm{~mm}$ [4]. Within the mountainous Baneh region, the livelihood system is comprised of three subsystems: traditional forestry, traditional animal husbandry and agriculture [4].The main occupation in the Blake village is animal husbandry, and goats are the main domestic animal. The people in this village like communities throughout the Baneh region are highly dependent on their forests to supply their fuel wood and fodder needs. Owing to the heavy snowfall that occurs during the winter in the Baneh region, this is a critical season for the people and their 
livestock. Winter fodder, obtained from the forest and stored for use during these winter months, is essential to sustain the livelihoods of the people here [4].

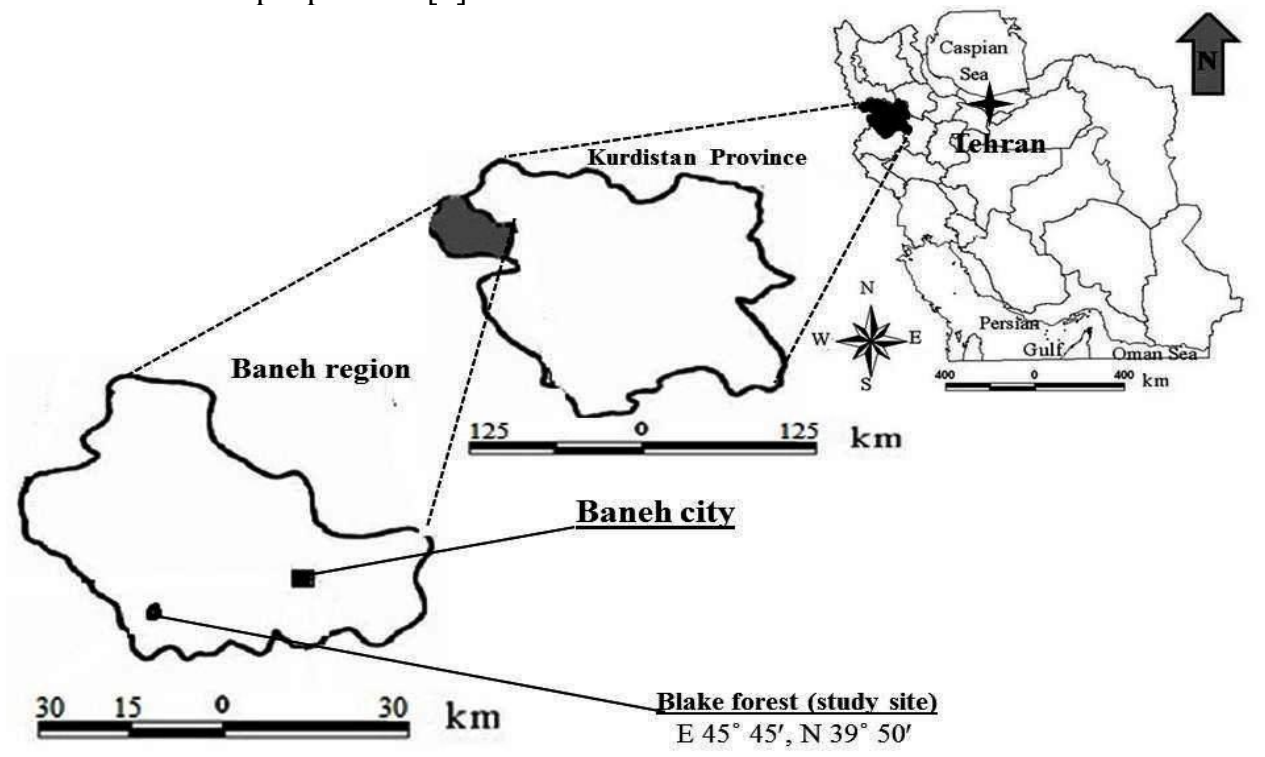

Figure 2. Location of study area, Blake Forest, Baneh region, Kurdistan Province, West of Iran I.2.2, Analysis

Three sample plots $(100 \mathrm{~m}$ by $100 \mathrm{~m}$ ) (total area of three plots $=3$ Hectare) based on sampling by random method were sampled. In every sample plot number of tree and shrub species, diameter at breast height $(\mathrm{DBH})$ and height $(\mathrm{m})$ were recorded. We applied indicators of Shannon Wiener $\left(\mathrm{H}^{\prime}\right)$ and Simpson (1-D) in order to analyses of biodiversity heterogeneity. Moreover, evenness was estimated using Margaleff indices as well (Table 1).to analysis of diversity indexes differences between DBH and high classes. Data analyzing was done by Ecological Methodology software (V.7). DBH, height, and dominant height were divided into six (0-10, 10-20, 20-30, 30-40, 40-50, and 50-60 cm), four (0-4, 4-8, 8-12 and $>12 \mathrm{~m})$, and three $(\mathrm{h}<1 / 3 \mathrm{hm}, 1 / 3 \mathrm{hm}<\mathrm{h}$ $<2 / 3 \mathrm{hm}$, and $\mathrm{h}>2 / 3 \mathrm{hm}$ ) classes, respectively.

Table 1: Biodiversity Indices used in this paper

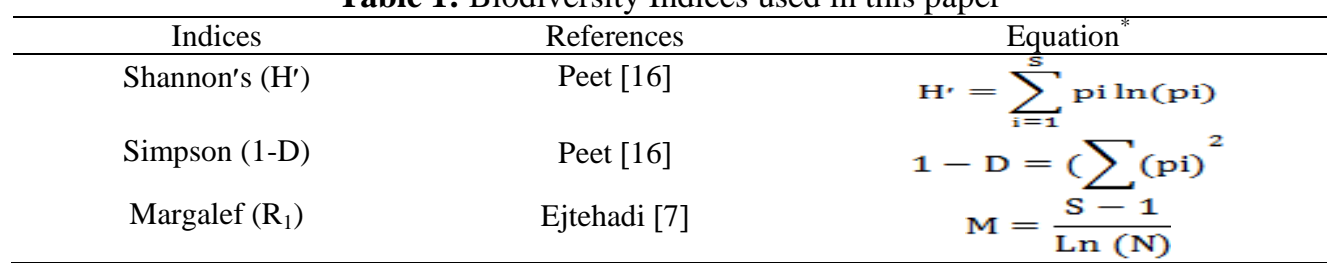

*S and pi refer to total number of species in the sample and proportion of individuals in the species, respectively.

Table 2. List of plant species (Tree, Shrub and Herbaceous) in the studied areas

\begin{tabular}{lcc}
\hline \multicolumn{1}{c}{ Scientific name } & Family & Trees/Shrubs \\
\hline Quercus libani Oliv. & Fagaceae & Tree \\
Quercus infectoria Oliv. & Fagaceae & Tree \\
Acer monspessulanum L. & Aceraceae & Tree \\
Crataegus persica C. pojark. & Rosaceae & Tree \\
Pistacia khinjuk stocks. & Anacardiaceae & Tree \\
Pyrus communis L. & Rosaceae & Tree \\
Amygdalus Communis L. & Rosaceae & Shrub \\
Cotoneaster morulus pojark & Rosaceae & Shrub \\
Lonicera nummularifolia Jaub\& spach. & Caprifoliaceae & Shrub \\
Amygdalus orientalis Duh. & Rosaceae & Shrub \\
\hline
\end{tabular}

The tree and shrub species belonged to four families and 10 tree species were identified in the study area (Table 1) thus for the classes of rosacea, fagaceae, aceraceae, and anacardiaceae, five, two, one, and one species were existed, respectively. 
Figure 3. Family name of tree and shrub in the study area

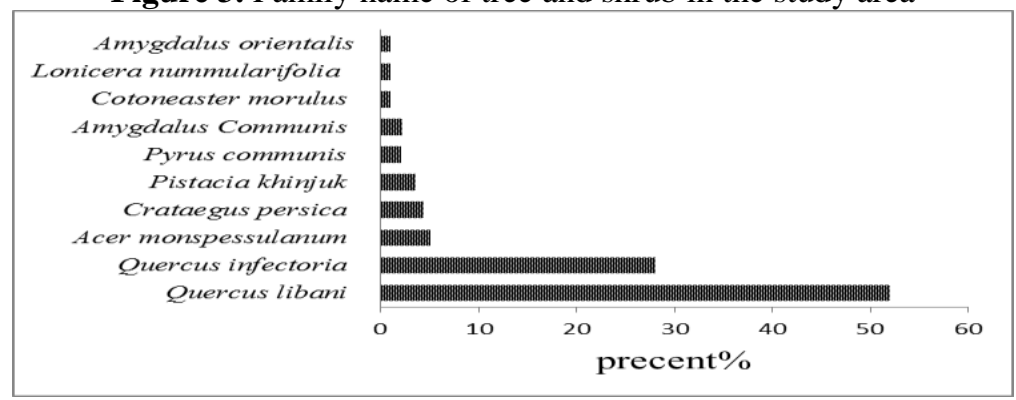

Figure 4. Comparison of tree and shrub Percent in the Blake forest

Results of figure 4 showed 10 tree and shrub species were observed in Blake forest. Quercus libani Oliv and Quercus infectoria Oliv were the most dominant woody plants in this area.

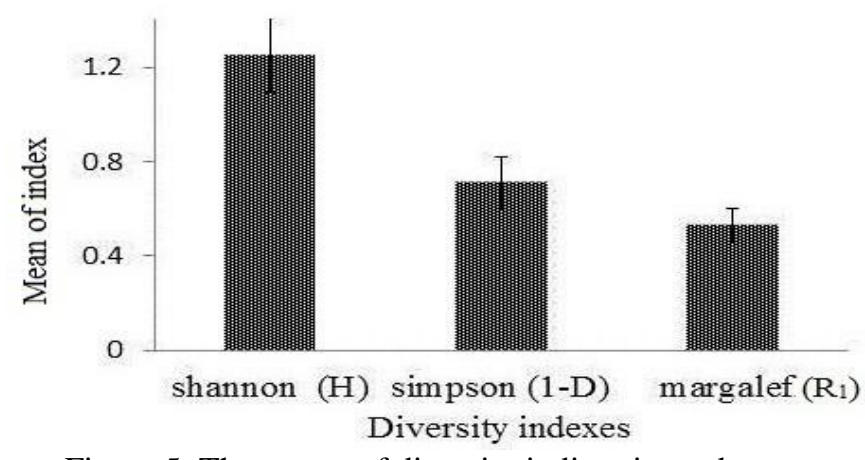

Figure 5. The means of diversity indices in study area

The results of Figure 5 showed that the computed tree species diversity index is as follows as: mean species Shannon index: 1.25 and 1.05, Simpson index: 0.71 and 0.64 , Margaleff index: 0.53

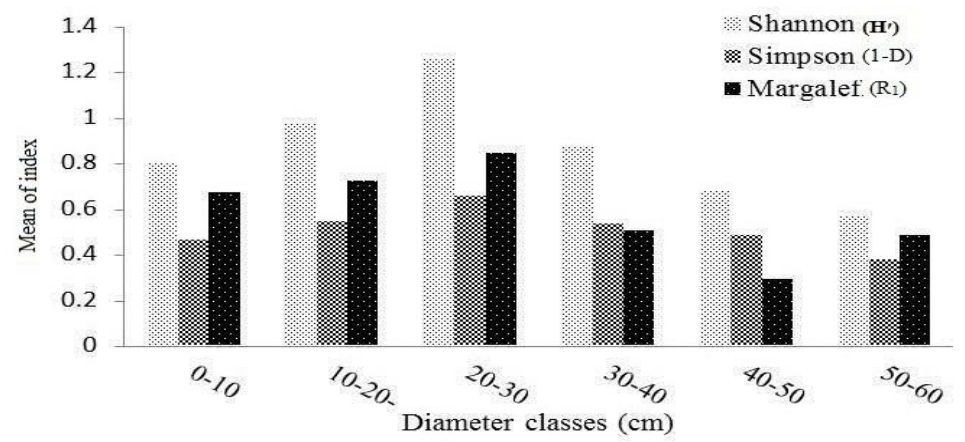

Figure 6. The comparison of diversity indices in $10 \mathrm{~cm}$ diameter classes.

The results of Figure 6 showed that the decrease process with the increase of diameter classes. The diversity index in the diameter classes of $0-10,20-30 \mathrm{~cm}$ and the least diversity index is in class of $50-60 \mathrm{~cm}$. The diameter classes (10-20, 30-40 and 40-50) are not significant different. The different is between diameter classes in level of $1 \%$ was significant. 


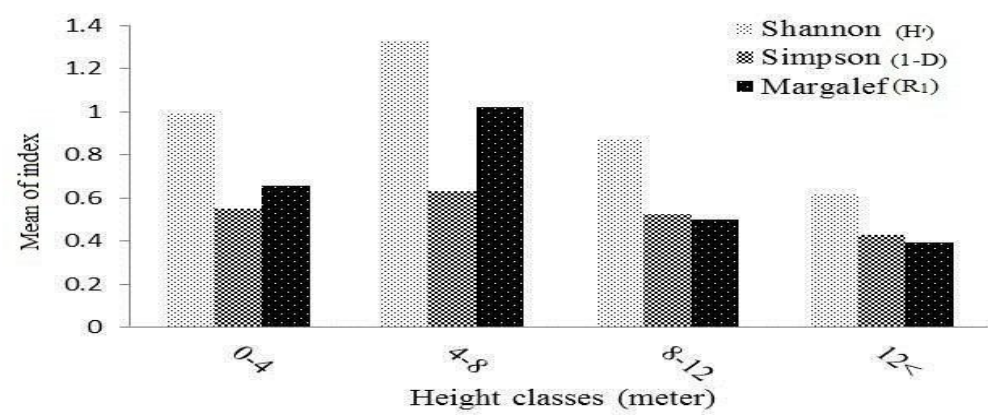

Figure 7. The comparison of diversity indices in $4 \mathrm{~m}$ height classes.

The results of Figure 7 showed the diversity indices have orderly decrease process. Maximum diversity index was in the height class of $0-4,4-8 \mathrm{~m}$ and the least diversity index in height class $12<\mathrm{m}$. the different is between height classes in level of $1 \%$ was significant.

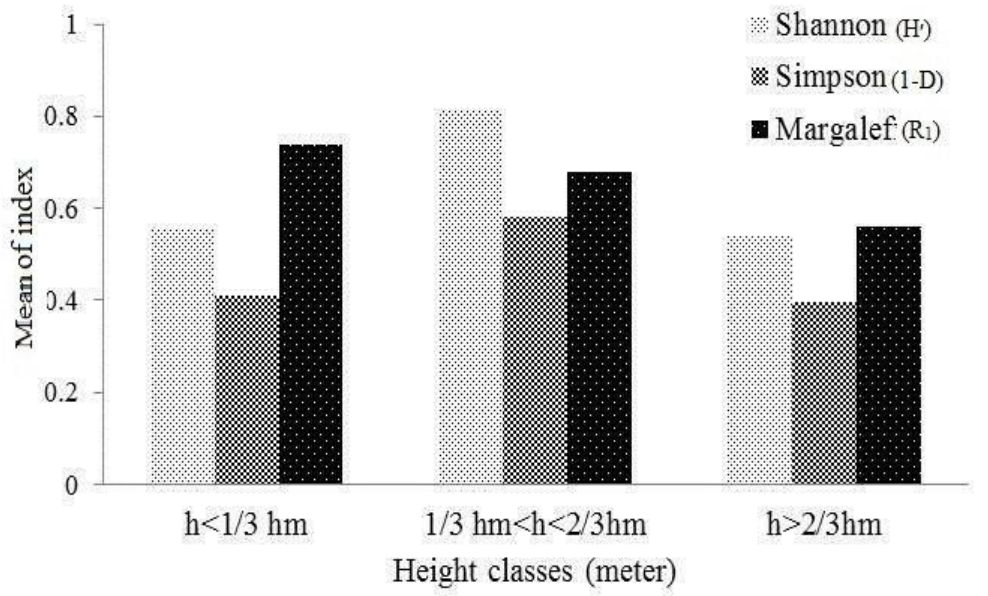

Figure 8 . The comparison of diversity indices in height classes by dominant height.

The results of Figure 8 showed that maximum diversity index was in $\mathrm{h}$ classes of $<1 / 3 \mathrm{hm}$. Diversity indices decreased by increasing dominant height. Total height class had significant different in level of $1 \%$.

Table 3.The results of Anova test to compered the means diversity index in structure diversity characteristic.

\begin{tabular}{|c|c|c|c|c|c|}
\hline $\begin{array}{l}\text { Structure } \\
\text { characteristic }\end{array}$ & Diversity index & df & $\begin{array}{l}\text { Mean } \\
\text { Square }\end{array}$ & $\mathrm{F}$ & Sig. \\
\hline \multirow{6}{*}{$\begin{array}{l}\text { Diameter } \\
\text { classes }\end{array}$} & Shannon $\left(\mathrm{H}^{\prime}\right)$ & 5 & 20.896 & 10.273 & .000 \\
\hline & & 891 & 2.034 & & \\
\hline & Simpson (1-D) & 5 & 4.381 & 2.254 & .084 \\
\hline & & 891 & 1.943 & & \\
\hline & Margalef (R1) & 5 & 3.297 & 6.105 & .000 \\
\hline & & 891 & 0.54 & & \\
\hline \multirow{6}{*}{ Height classes } & Shannon $\left(\mathrm{H}^{\prime}\right)$ & 3 & 28.111 & 11.159 & .000 \\
\hline & & 893 & 2.519 & & \\
\hline & Simpson (1-D) & 3 & 6.491 & 2.229 & .078 \\
\hline & & 893 & 2.912 & & \\
\hline & Margalef (R1) & 3 & 4.891 & 10.844 & .000 \\
\hline & & 893 & 0.451 & & \\
\hline \multirow{6}{*}{$\begin{array}{c}\text { dominant } \\
\text { height classes }\end{array}$} & Shannon $\left(\mathrm{H}^{\prime}\right)$ & 2 & 22.45 & 16.519 & .000 \\
\hline & & 894 & 1.359 & & \\
\hline & Simpson (1-D) & 2 & 6.008 & 3.152 & .045 \\
\hline & & 894 & 1.906 & & \\
\hline & Margalef (R1) & 2 & 7.406 & 9.731 & .000 \\
\hline & & 894 & 0.761 & & \\
\hline
\end{tabular}

Result table 3 indicated the differences between tree diversity indexes in the diameter, Height and dominant heights were statistically significant. 


\section{IV.1, Disscusion}

\section{Conclusion}

Species biodiversity is used greatly in vegetation studies, and environmental evaluation is one of the main criteria to determine ecosystems condition [12]. All three calculated indices in this study have been mentioned as the most applicable indices [12,14]. Forest structure is the important feature in management of forest ecosystems [20]. The study of forest stand profile especially in virgin forests is very important and gives us comprehensive information about structure of these forests[13]. To better understanding of forest stand structure, we analyzed it according to the vertical and horizontal structure. Species diversity of trees and shrubs in low diameter and height classes were significantly different with high diameter and height classes. Trees are the main elements in forest ecosystems therefore removing of trees will threaten the life of the creatures in this ecosystem [13]. The results this study showed that the Shannon $(\mathrm{H})$ index had maximum quantity between all indexes. Moreover, Rosacae family had high number of species (Figure 3). 10 tree and shrub species were observed in Blake forest and Quercus libani Oliv and Quercus infectoria Oliv were the most dominant woody plants in this area (Figure 4). In this study, by increasing the diameter and height classes, the diversity decreased (Figures 6 and 7). The diameter classes of $0-10$ and $20-30 \mathrm{~cm}$ had maximum diversity index in the diameter classes. Results showed that maximum diversity index were in the height classes of $0-4,4-8 \mathrm{~m}$. by increasing of tree size (i.e. diameter and height) tree diversity decreased. Also, by increasing of diameter and height classes, the diversity decreased because gradually increase of trees age dominant species dominant against the under species and tree diversity decreased. The comparison of tree diversity in the classes of $10-20 \mathrm{~cm}$ and 20 $30 \mathrm{~cm}$ showed that classes of $20-30 \mathrm{~cm}$ has higher diversity index. Because traditional forest management practices in the Kurdistan Province is prune tree crowns and regulate yields from forest and negative effect on the tree diversity. Result indicated the differences between tree diversity indexes in the diameter, Height and dominant heights were statistically significant (table 3). Shorabi et al (2011) showed that the diameter class of 0 $-10 \mathrm{~cm}$ and height class of $0-10 \mathrm{~m}$ has higher diversity. In our study diameter and height classes of $0-10 \mathrm{~cm}$ and $0-4 \mathrm{~m}$, respectively, were the highest tree diversity. Ahani et al (2006) showed that the Shannon and N1 Mac Arthur indices in diameter class of $35-50 \mathrm{~cm}$ have greatest amount and in the front in our study diameter and height classes $0-10 \mathrm{~cm}$ and 0-4 meter was the highest tree diversity. In this step choosing of trees perform by considering of target diameter from defined species and gradually the number of trees in defined diameter decreased and so the repeating act might remove some classes of trees. It is threatened the structure diversity and the species diversity. Any changes in above level might change the ground cover. Tree dimension diversity has an effect on the amount of light and raining by small plant and trees (Anderson et al. 1969). This can influence on the produce of forest ecosystems.

\section{IV.2, Conclusion}

The increasing of diameter and height classes decreased species diversity. A significant different was observed for diversity index between diameter and height classes. Hence, the study of biodiversity changes in different diameter and height category cause ecologically precise perspective in management of forest stands.

\section{Acknowledgements}

We thank Mr. Omid Fathizadeh, Asghar Farajolahi, Vahid Rizvandi and Sasan Vafaei for their help in the field and we thank Dr. Foad Fatehi and Dr. Hamid Jalilvand for their help in the analysis of data.

\section{References}

[1] H. Ahani, H, Pourbabaei and AE. Bonyad, Investigation of trees species diversity based on diameter at breast height (dbh) class on Norway Maple (Acer platanoides L.) in Shafarood Forest (Guilan Province). J Agric Sci 12 (3), 2006, 525-533.

[2] RC. Anderson, OL. Loucks and AM. Swain, Herbaceous response to as soil indicators in Oregon's western cascades old-growth forests. Northwest boreal coniferous forests. Ecology 50, 1969, 255-263.

[3] P. V. Baev and L.D Penev, BIODIV. Program for calculating biological diversity parameters, similarity, niche overlap, and cluster analysis. Version 5.1. Pensoft, 1995, 57p.

[4] S. Bayazidi, N. Saidi and Z. Khorshidi, Report of socio-economic studies. In project of traditional forest management in Havareh khol. Joint project of Daumoon (local NGO) with UNDP-GEF/SGP. Project No. IRA- 2002-018 (IRA98G52). 2003, 80 p.

[5] K. Browicz, Chorology of trees and shrubs in south-west Asia. Pozznn 57, 1994, 39-62.

[6] R. Costanza, B. Fisher, K. Muler, S. Liu and T. Christopher, Biodiversity and ecosystem services: A multi-scale empirical study of the relationship between species richness and net primary production. Ecol Econ 61, 2007, 478-491.

[7] H. Ejtehadi, A. Sepehry and HR. Akkafi, Method of measuring biodiversity. [Ferdowsi University of Mashhad Publication No. 530, 2009, Mashhad, IR Iran]

[8] M. Fattahi, (Study on Zagros oak forests and the most important their destruction causes. Institute of Forests and Rangelands Research press, 1994, Sanandaj). [Persian]

[9] S. Jamshidiyan, Report of conventional ownerships. In Project of traditional forest management in Havareh khol. Joint project of Daumoon (local NGO) with UNDPGEF/ SGP. Project No. IRA-2002-018 (IRA98G52). 2002, 80p (In Persian.)

[10] MH. Jazirehi and EM. Rostaghi, (Silviculture in Zagros. University of Tehran Press. Tehran, Iran, 2002, 560p) 
[11] J. Liang, J. Buongiorno, RA. Monserud, EL. Kruger and M. Zhou, Effects of diversity of tree species and size on forest basal area growth, recruitment, and mortality. For Ecol Manag 243, 2007, 116-127.

[12] HR. Mirdavoodi and H. Zahedi Pour, Determination of suitable species diversity model for Meghan playa plant association and effect of some ecological factors on diversity change. Pajuhesh \& Sazandegi 68, 2005, 56-65.

[13] Marvi-Mohajer. MM, Silviculture (Tehran University Press, 2005, Tehran,380p) GO. Oheimb, Ch. Westphal, H. Tempel, and W. Hardtle, Structural pattern of a near natural beech forest (Fagus sylvatica) (Serrahn, North-east Germany). For Ecol Manag 212, 2005, 253-263.

[14] V. Neufeldt, D. Guralink and B. Websters, New World dictionary, Third College Edition, Simon and Schuster. New York, in: Barnes, B.V., Zak, D.R., Denton, S.R. and [15] S.H. Spurr (Forest Ecology (4th edition). John Wiley and Sons Inc, 774)

[16] R.K. Peet, The measurement of species diversity. Ann. Rev. Ecol, Systematics 5, 1988, 285-307.

[17] H. Pourbabaei and KH. Dado, Species diversity of woody plants in the district No. 1 forests, Kelardasht, Mazandaran province. J Iran Biol 18, 2000, 306-322.

[18] V . Sohrabi, Comparing of species and stracture diversity in gradient of between Shastkolateh Beech Forest and Loveh Oak Forest [M.Sc thesis]. Faculty Forestry, Gorgan University of Agriculture Sciences and Natural Resources. Gorgan, IR Iran, 2010, 87p.

[19] A. Youngblooda, T. Maxb and K. Coe, Stand structure in eastside old-growth ponderosa pine forests of Oregon and northern California.For Ecol Manag 195, 2004, 238-256.

[20] EK. Zenner and DE. Hibbs, A new method for modeling the heterogeneity of forest structure. For Ecol Manag 129, $2000,75-87$.

[21] O. Fathizadeh, P. Attarod, TG. Pypker, AA. Darvishsefat and G.Zahedi Amiri, Seasonal Variability of Rainfall Interception and Canopy Storage Capacity under Individual oak (Quercus brantii) Trees of Western Iran. Journal of Agricultural Science and Technology 15, 2012.

[22] Forest and Rangeland Organization of Iran, Strategies for sustainable forest management in Zagros forests. Technical Report. Forest and Rangeland Organization, Teheran,Iran, 2002, 70 p.

[23] H. Ghazanfari, M. Namiranian, H. Sobhani and M.R. Marvi Mohajer, Traditional forest management and its application to encourage public participation for sustainable forest management in the northern Zagros mountain of Kurdistan province, Iran. Scandinavian Journal of forest science, 19 (4), 2004, 65-71.

[24] GO. Oheimb, Ch. Westphal, H. Tempel, and W. Hardtle, Structural pattern of a near natural beech forest (Fagus sylvatica) (Serrahn, North-east Germany). For Ecol Manag 212, 2005, 253-263.

[25] T. Eftekhari and M. Ramezani, Introduction to Plant Biodiversity in Iran. In: Biodiversity and Medicinal Plant Wealth of South Asian Countries. (eds). P. Pushpangadan, K.N. Nair and M.R. Ahmad P.39-40. National Botanical Research Institute, Lucknow226001, 2004, In dia. 